\title{
A test for the dihydroxyacetone phosphate pathway
}

We know that liver slices selectively produce species of phosphatidates containing saturated acids at the primary position and principally monoenes and dienes at the secondary ${ }^{1}$. Since isolated microsomal preparations from guinea pig ${ }^{2}$ and pigeon ${ }^{1}$ liver did not show a selective placement of palmitate or stearate at the Iposition of phosphatidate, the hypothesis of $\mathrm{HAJRA}^{3}$ was tested as a possible explanation. The incorporation of exogenous $\left[{ }^{14} \mathrm{C}\right] \mathrm{glycerol}$ via sn-glycerol 3-phosphate, dihydroxyacetone phosphate and acylation of dihydroxyacetone phosphate in mitochondria might lead to radioactive acyldihydroxyacetone phosphate and acyl-sn-glycerol 3-phosphate which could then yield phosphatidates with microsomes. This latter pathway could be presumed to have a higher specificity ${ }^{3}$ than the direct microsomal acylation of sn-glycerol 3-phosphate. The low specificity reported earlier ${ }^{1,2}$ might then be presumed due to the absence of the selective dihydroxyacetone phospliate pathway in those preparations.

The following experiments were designed to test whether exogenous glycerol was entering the selectively acylated, newly formed species of phosphatidates in slices of rat liver with an obligatory loss of the proton on carbon atom 2.

Slices were prepared with a Stadie-Riggs slicer from perfused livers. The slices (2-3 g wet weight), 0.I $\mu$ mole of a mixture of $\left[\mathrm{I}(3)^{-14} \mathrm{C}\right] \mathrm{glycerol}(\mathrm{I} .28 \mu \mathrm{C})$ and $\left[2{ }^{3} \mathrm{H}\right]-$ glycerol $\left(5.10 \mu \mathrm{C}\right.$ ) (Amerscham/Searle Corp.), $75 \mu$ moles of $\mathrm{MgCl}_{2}$ and ATP, and 1.5 $\mu$ moles of $\mathrm{CoA}$ were incubated in $\mathrm{I} 2 \mathrm{ml}$ of Krebs-Ringer phosphate buffer with constant shaking at $37^{\circ}$ for $30 \mathrm{~min}^{1}$. Slices were rinsed, blotted and homogenized in $50 \mathrm{ml}$ of chloroform-methanol (I:I, by vol.) with a VirTis homogenizer. Proteins were removed by filtration and the extracts were washed with 0.2 vol. of $0.58 \% \mathrm{NaCl}$ and with 0.2 vol. of "pure upper phase" as described by Folch et al. ${ }^{4}$. Labelled lipids were separated by thin-layer chromatography on Silica Gel H with chloroform-ethanol$88 \%$ formic acid-water (roo:50:5:4, by vol.). Analysis of the distribution of radioactivity on the thin-layer chromatograms showed that more than $60 \%$ of the labelled lipids was diacyl-sn-glycerol 3 -phosphate and about $20 \%$ was neutral lipid. Diacyl$s n$-glycerol 3 -phosphate was extracted from the appropriate area on the thin layer by treating the silicic acid twice with $5 \mathrm{ml}$ of chloroform-methanol ( $\mathrm{I}: 2$, by vol.) and twice with $5 \mathrm{ml}$ of chloroform-mcthanol-1.5\% $\mathrm{NH}_{4} \mathrm{OH}(6: 5: 1$, by vol.). The diacyl $s n$-glycerol 3 -phosphate was hydrolyzed by chicken liver phosphatidate phosphohydrolase $e^{5}$ and the 1,2-diacylglycerol was converted to 2-monoacylglycerol by partial ly purified pancreatic lipase ${ }^{6}$. The 2 -monoacylglycerol was acylated with heptadecanoyl anhydride to triacylglycerols which were separated into species, according to the varied degree of unsaturation of the 2-ester, by thin-layer chromatography on silver nitrate-Silica Gel G $(10 \%, \mathrm{w} / \mathrm{w})$ as described by Hrll et al. ${ }^{1}$. Radioactivity was counted in a Packard Tri-Carb scintillation spectrometer using aqueous dioxane scintillation fluid?

The results are shown in Table $I$. As in earlier work ${ }^{\mathbf{1}}$, the principal products contained oleate $(25 \%)$ and linoleate $(32 \%)$ esterified at the 2 -position. Lesser amounts of polyene and saturated acids were incorporated into the 2 -ester of phosphatidate.

The exogenous glycerol was esterified with a specificity very close to that 
TABLE I

COMPOSITION OF FATTY ACIDS AT THE 2-POSITION OF THE GLYCEROL NEWIY INCORPORATED INTO PHOSPHATIDATES

The 2-acylglycerol unit from diacyl-sn-glycerol 3-phosphate as the I,3-diheptadecanoyl-2-acylglycerol derivative was separated into species by silver ion-thin-layer chromatography. Lipid was eluted from individual bands for counting purposes. Data in the parentheses are cited from the earlier work by Hill et al. ${ }^{1}$.

\begin{tabular}{|c|c|c|c|c|c|}
\hline \multirow{2}{*}{$\begin{array}{l}\text { Band } \\
\text { designation }\end{array}$} & \multicolumn{4}{|c|}{ Distribution of radioactivity } & \multirow[t]{2}{*}{${ }^{3} \mathrm{H} /{ }^{14} \mathrm{C}$} \\
\hline & \multicolumn{2}{|c|}{ Percentage } & $\begin{array}{l}{ }^{14} \mathrm{C} \\
\text { (counts/min) }\end{array}$ & $\begin{array}{l}{ }^{3} \mathrm{H} \\
\text { (counts/min) }\end{array}$ & \\
\hline Saturated & I3 & (6) & 1264 & 737 & $0.5^{8}$ \\
\hline Monvene & 25 & $(26)$ & 2362 & 1383 & 0.59 \\
\hline Unidentified & 7 & $(\mathrm{I})$ & 692 & 401 & 0.58 \\
\hline Diene & 32 & (39) & 3028 & 1792 & 0.59 \\
\hline Triene & 3 & (I) & 289 & 145 & 0.50 \\
\hline Tetraene & 5 & (16) & $5 \times 5$ & 269 & 0.52 \\
\hline$>5$ & 6 & & 528 & 258 & 0.49 \\
\hline \multirow[t]{2}{*}{ Origin } & 8 & $(9)$ & $7 \times 8$ & $43^{8}$ & $0.6 \mathrm{I}$ \\
\hline & & & & ${ }^{3} \mathrm{H} /{ }^{14} \mathrm{C}$ substra & 0.47 \\
\hline
\end{tabular}

observed in earlier work with rat liver slices ${ }^{1}$. This specific pattern does not seem due to action of a dihydroxyacetone phosphate pathway since such action would have removed the ${ }^{3} \mathrm{H}$ from the glycerol. In fact, the results give no evidence for any of the exogenous precursor being used in that pathway. Rather, the slight isotopic enrichment suggests that the enriched glycerolphosphate, rather than dihydroxyacetone phosphate, was the substrate for lipid synthesis. The ${ }^{3} \mathrm{H}$ to ${ }^{14} \mathrm{C}$ ratio of the water-soluble fractions obtained by washing the chloroform-methanol extracts was 0.39 , indicating that some removal of the ${ }^{3} \mathrm{H}$ from glycerol did occur and the products appeared as water-soluble compounds. Although some endogenous dihydroxyacetone phosphate might serve in phosphatidate synthesis, the present results indicate that the acylation of glycerol by intact liver slices can be sufficiently selective to provide the expected species of monoenes and dienes without involving the keto intermediate. The factors regulating selective placement of acids in newly formed glycerides must, then, be found elsewhere. Service.

This work was supported by grant AM-05310 from the U.S. Public Health

Department of Biological Chemistry, The University of

HarUmI OKUYAMA Michigan, Ann Arbor, Mich. 48 ro4 (U.S.A)

I E. E. Hill, D. R. Husbandos and W. E. M. Lands, J. Biol. Chem, 243 (I968) 4440.

2 W. E. M. LANDS and P. HART, $f$. Lipid Res., 5 (1964) $8 \mathbf{I}$.

3 A. K. Ha.tra, J. Biol. Chem., 243 (Ig68) 3458.

4 J. Folch, M. Lees and G. H. Sloane-Stanley, J. Biol. Chem., 226 (I957) 497.

5 S. W. Smith, S. B. Weiss and E. P. Kennedy, J. Biol. Chem., 228 (1957) 915.

6 W. E. M. Lands, R. A. Pieringer, S. P. M. Slakey and A. Zschocke, Lipids, I (1966) 444.

7 F. SNXoer, Anal. Biochem, $9(1964) \times 83$.

Received August 3rd, r970

Biochim. Biophys. Acta, $2 \times 8(x 970) 376-377$ 